\title{
Application of multi-residue analytical method for determination of 496 pesticides in frozen gyoza dumplings by GC-MS and LC-MS
}

\author{
Tomofumi MatsuoKa, ${ }^{*}$ Yumi AkiYama and Takao Mitsuhashi \\ Hyogo Prefectural Institute of Public Health and Consumer Sciences, \\ Arata-cho 2-1-29, Hyogo-ku, Kobe, Hyogo 652-0032, Japan
}

(Received March 9, 2011; Accepted June 7, 2011)

\begin{abstract}
The applicability of multi-residue analytical method for 496 pesticides (including metabolites) in frozen gyoza dumplings was verified. This method involved extraction using aqueous acetonitrile (around $70 \%$ of acetonitrile content) followed by cleanup using octadecylsilyl (ODS) and primary secondary amine (PSA) mini-column solid-phase extraction (SPE). The target compounds were determined by gas chromatography-mass spectrometry (GC-MS) and liquid chromatography-mass spectrometry (LC-MS). Validation tests were performed on frozen gyoza dumplings fortified at 0.01 and $0.10 \mu \mathrm{g} / \mathrm{g}$ in accordance with the guideline issued by the Japanese Ministry of Health, Labour and Welfare. Among the 496 pesticides tested, 378 pesticides were found to conform to the guideline when the solvent standard was used, and 432 pesticides conformed when the matrix-matched standard was used, respectively. The limits of quantitation $(\mathrm{S} / \mathrm{N} \geq 10)$ were set at $0.01 \mu \mathrm{g} / \mathrm{g}$ for all, except 20 of the pesticides that were tested. Although no significant matrix effects were observed for most of the pesticides, the use of the matrix-matched standard was preferable to the solvent standard for accurate quantitation. The method was applied to 11 commercial samples, and 14 different pesticides were detected from 8 samples at concentrations ranging from trace levels $(<0.01 \mu \mathrm{g} / \mathrm{g})$ to $0.11 \mu \mathrm{g} / \mathrm{g}$. C Pesticide Science Society of Japan
\end{abstract}

Keywords: pesticide, multi-residue, frozen gyoza dumpling, GC-MS, LC-MS, validation.

Electronic supplementary material The online version of this article contains supplementary material (Supplemental Tables S1-S3), which is available at http://www.jstage.jst.go.jp/browse/jpestics/.

\section{Introduction}

The Japanese Ministry of Health, Labour and Welfare (MHLW) introduced the positive list system for agricultural chemicals in 2006, and established maximum residue limits (MRLs) for about 800 substances $^{1)}$ and the uniform limit $\left.(0.01 \mu \mathrm{g} / \mathrm{g}){ }^{2}{ }^{2}\right)$ Although processed foods became the object of regulation by the positive list system, MRLs were established for only a fraction of the foods that are made from a single ingredient (such as cooking oil, cereal processed food, dried fruit and fruit juice). Other processed foods were regulated whether the ingredients meet the MRLs or not, but it is difficult to identify an ingredient in which pesticide could be detected. Therefore regulatory monitoring for processed foods was scarcely performed.

\footnotetext{
* To whom correspondence should be addressed. E-mail: Tomofumi_Matsuoka@pref.hyogo.lg.jp Published online September 4, 2011

(C) Pesticide Science Society of Japan
}

However, food-poisoning outbreaks caused by organophosphorous pesticide in frozen gyoza dumplings were occurred in December 2007 and January 2008, and there were rising concerns about processed foods. These concerns led to an urgent requirement for the analysis of residual pesticides not only in agricultural products but also in processed foods. The official method was only applied to organophosphorous pesticides, and a large number of multi-residue methods were studied. ${ }^{3-9)}$ In most of them, ethyl acetate ${ }^{3-5)}$ or acetonitrile ${ }^{6-8)}$ were used as the extracting solvents. Ethyl acetate is suitable for the extraction of pesticides in lipids and lipophilic compounds which are contained in significant quantities in some kinds of processed foods, but time-consuming cleanup processes such as acetonitrile/hexane partitioning are required to detect residues at the uniform limit level. The amounts of lipophilic compounds that are extracted by acetonitrile are lower than those extracted by ethyl acetate, although there is concern that the extraction efficiency of some lipophilic pesticides is reducing.

We have developed a multi-residue analytical method for 
more than 500 pesticides in agricultural products, involving extraction with acetonitrile and determination by gas chromatography-mass spectrometry (GC-MS) and liquid chromatography-mass spectrometry (LC-MS).$^{10)}$ This method was applied to the regulatory monitoring of 200 samples a year in our institution. ${ }^{11,12)}$ Furthermore, we applied the method to studies into the daily intake of pesticide residues in each food group, and we found that we could generate successful results for fish and shellfish, meat and dairy products, which are lipid-rich foods. ${ }^{13)}$ This suggested that the method could have applicability to processed foods.

In this study, we evaluated the utility of our developed method for processed foods using frozen gyoza dumplings as an example, because a frozen gyoza dumpling was a relatively lower-lipid processed food (its lipid content is about 8\%) than other processed foods such as a broiled eel and a canned beef (their lipid contents are about 20\%). ${ }^{14)}$ Validation was performed in accordance with the guideline showed by MHLW. ${ }^{15)}$ As a result, among the 496 pesticides that we tested (organophosphorous, 101; organonitrogen, 288; organochlorine, 44; $N$-methylcarbamate, 24; pyrethroid, 22; other, 17 pesticides), 432 met the acceptance criteria of the guideline. The method was applied to frozen gyoza dumpling samples to verify its utility in routine analysis.

\section{Materials and Methods}

\section{Chemicals and reagents}

Acetone, acetonitrile, and anhydrous sodium sulfate (Wako Pure Chemical Ind., Japan), $n$-hexane and sodium chloride (Kanto Chemical, Japan) were of pesticide analysis grade. The acetonitrile (Wako) that we used for LC-MS was of liquid chromatography grade, and the others were of analytical grade. As an internal standard (IS) solution, triphenylphosphate (TPP) (Wako) and 1-ethyl-3-phenylurea (EPU) (Frinton Laboratories, USA) were mixed at 5 and $10 \mu \mathrm{g} / \mathrm{mL}$ with acetone- $n$-hexane $(1: 4)$. IS solution was added except to the blank sample.

Octadecylsilyl (ODS) mini-column: Isolute C18 (endcapped), $2 \mathrm{~g}$ (Biotage, Sweden) was conditioned with $10 \mathrm{~mL}$ acetonitrile and $10 \mathrm{~mL}$ water; Primary secondary amine (PSA) mini-column: Isolute PSA, $500 \mathrm{mg}$ (Biotage) was conditioned with $6 \mathrm{~mL}$ acetone- $n$-hexane $(1: 1)$.

The pesticides and their metabolites were obtained from Wako, Kanto, Sigma-Aldrich, Hayashi Pure Chemical Ind. (Japan) and Dr. Ehrenstorfer (Germany). Individual stock standard solutions $(250 \mu \mathrm{g} / \mathrm{mL})$ were prepared with acetone. Organochlorine, pyrethroid and unstable pesticides in acetone ( 3 pesticides: dicofol, etrimfos and iprodione) were prepared with $n$-hexane. Mixed standard solutions each containing 20-30 compounds at $10 \mu \mathrm{g} / \mathrm{mL}$ were prepared from stock solutions. A working standard solution of each pesticide at $1.0 \mu \mathrm{g} / \mathrm{mL}$ was prepared from mixed solutions with acetone. Solvent standard solutions for GC-MS analysis were prepared by evaporating 0.1 or $1.0 \mathrm{~mL}$ working standard and $0.10 \mathrm{~mL}$
IS solution under a gentle stream of nitrogen, and dissolving with $2.0 \mathrm{~mL}$ acetone- $n$-hexane $(1: 4)$. Solvent standard solutions for LC-MS analysis were prepared by evaporating $0.4 \mathrm{~mL}$ of each standard solution for GC-MS under a gentle stream of nitrogen, and dissolving with $0.2 \mathrm{~mL}$ acetonitrile. Matrix-matched standard solutions for GC-MS and LC-MS were prepared by evaporating blank sample extracts and dissolving with each concentration of the solvent standard solutions.

\section{Apparatus}

\subsection{GC-MS system}

The Agilent $6890 \mathrm{~N}$ gas chromatograph connected to an Agilent 5973 inert mass spectrometer (Agilent Technologies, USA) was used. GC separation was performed on a HP-5MS ( $30 \mathrm{~m} \times 0.25 \mathrm{~mm}$ i.d., film thickness $0.25 \mu \mathrm{m}$; Agilent Technologies) with a guard column ( $c a .50 \mathrm{~cm} \times 0.25 \mathrm{~mm}$ i.d., noncoating).

2.2. LC-MS system

The Agilent 1100 series liquid chromatograph, connected to an Agilent MSD SL mass spectrometer (Agilent Technologies) equipped with an electrospray interface (ESI) operating in both positive and negative ion modes was used. LC separation was performed on an Ascentis Express C18 $(100 \mathrm{~mm} \times$ $3.0 \mathrm{~mm}, 2.7 \mu \mathrm{m}$; Sigma-Aldrich) with an Inertsil ODS3 guard column $(10 \mathrm{~mm} \times 3.0 \mathrm{~mm}, 3 \mu \mathrm{m}$; GL Sciences). Acetonitrile and $10 \mathrm{mM}$ ammonium acetate aqueous solution were used as the mobile phase at a flow rate of $0.5 \mathrm{~mL} / \mathrm{min}$. In gradient-elution analysis, the first mobile phase was $15 \%$ acetonitrile, increased linearly to $95 \%$ in $16 \mathrm{~min}$, and held at $95 \%$ for $9 \mathrm{~min}$.

The operating conditions for GC-MS and LC-MS were as described in a previous paper ${ }^{10)}$. Analytical informations for GC-MS and LC-MS, such as retention time and the monitor ion for each pesticide, were shown in Supplemental Table S1-S2.

\section{Sample preparation}

All of the food samples were collected at local markets in the Hyogo Prefecture during 2008-2009. The samples were chopped in a food processor and stored at $-20^{\circ} \mathrm{C}$ until analysis. The samples, fortified with 496 pesticides at $0.01 \mu \mathrm{g} / \mathrm{g}$ and $0.10 \mu \mathrm{g} / \mathrm{g}$, were prepared daily for recovery tests. For recovery test, $0.10 \mathrm{~mL}$ or $1.0 \mathrm{~mL}$ working standard solution and $0.10 \mathrm{~mL}$ IS solution were added to $10 \mathrm{~g}$ sample. After standing for $30 \mathrm{~min}$, the sample preparation was performed as described below.

The sample preparation was nearly performed as previously described. ${ }^{10)}$ A $10 \mathrm{~g}$ portion of chopped sample was extracted with $15 \mathrm{~mL}$ water and $60 \mathrm{~mL}$ acetonitrile, and then filtered. The filtrate was cleaned up using an ODS mini-column, and then acetonitrile was separated by salting-out with $10 \mathrm{~mL}$ of $2 \mathrm{M}$ phosphate buffer saturated brine solution $(\mathrm{pH} \mathrm{7})$ and $6 \mathrm{~g}$ sodium chloride. A $45 \mathrm{~mL}$ aliquot of acetonitrile layer was collected and evaporated to dryness. The residue was dis- 


\section{Sample 10g}

Extract with $15 \mathrm{~mL}$ water $+60 \mathrm{~mL}$ acetonitrile

\section{Extracts}

Filter

\section{ODS mini-column (2 g) cleanup}

Load all filtrate and collect all elute

\section{Salting-out}

Evaporate $45 \mathrm{~mL}$ of acetonitrile layer

Adjust to $3 \mathrm{~mL}$ with acetone- $n$-hexane (1:1)

\section{PSA mini-column (500 mg) cleanup}

Load a $2 \mathrm{~mL}$ aliquot

Elute with $9 \mathrm{~mL}$ acetone- $n$-hexane $(1: 1)$

Collect all elute and evaporate

Adjust to $1 \mathrm{~mL}$ with acetone- $n$-hexane (1:4)

Redissolve in acetonitrile

\section{GC-MS LC-MS}

Fig. 1. Sample preparation method for pesticides in frozen gyoza dumplings.

solved in acetone- $n$-hexane $(1: 1)$ and adjusted to $3 \mathrm{~mL}$. A $2 \mathrm{~mL}$ aliquot was loaded on a PSA mini-column and eluted with $9 \mathrm{~mL}$ acetone- $n$-hexane $(1: 1)$, and then the eluate was evaporated to dryness. The residue was dissolved in $1 \mathrm{~mL}$ acetone- $n$-hexane $(1: 4)$ for GC-MS analysis, and an aliquot of the solution was evaporated and redissolved in acetonitrile for LC-MS analysis. Figure 1 summarizes the procedure.

\section{Validation test}

To prove its validity, the developed method must meet the criteria for certain validation characteristics. The validation characteristics to be considered are selectivity, limit of quantitation (LOQ), recovery and precision. ${ }^{15)}$ The evaluation of these parameters was conducted as previously described. ${ }^{16)}$ Briefly, selectivity: the absence of interference peaks for the quantitation of target compounds was confirmed by analysis of a blank sample; LOQ: LOQ was set at $0.01 \mu \mathrm{g} / \mathrm{g}$ and it was judged whether the peak of each pesticide corresponding to

Table 1. Acceptance criteria for recovery and precision

\begin{tabular}{ccccc}
\hline $\begin{array}{c}\text { Fortified } \\
\text { level } \\
(\mu \mathrm{g} / \mathrm{g})\end{array}$ & $\begin{array}{c}\text { Number } \\
\text { of trials }\end{array}$ & $\begin{array}{c}\text { Mean } \\
\text { recovery } \\
(\%)\end{array}$ & $\begin{array}{c}\text { Repeatability } \\
(\text { RSD \%) }\end{array}$ & $\begin{array}{c}\text { Intermediate } \\
\text { precision } \\
(\text { RSD \%) }\end{array}$ \\
\hline 0.01 & $\geq 5$ & $70-120$ & $<25$ & $<30$ \\
0.10 & $\geq 5$ & $70-120$ & $<15$ & $<20$ \\
\hline
\end{tabular}

$0.01 \mu \mathrm{g} / \mathrm{g}$ was $\mathrm{S} / \mathrm{N} \geq 10$; accuracy (recovery) and precision: the recovery test was conducted with a nested design to evaluate repeatability and intermediate precision at the same time.

Table 1 shows the acceptance criteria for recovery and precision at each fortified level. The proposed method was evaluated for mean recovery, repeatability and intermediate precision in accordance with these criteria.

\section{Results and Discussion}

\section{Validation test}

\subsection{Selectivity}

Table 2 shows the pesticides that didn't meet the criteria for selectivity. These 15 pesticides could not be quantitated with both target ions and qualifier ions, owing to interference peaks that were detected in both GC-MS and LC-MS analysis. All of them were targets for LC-MS analysis except for dioxathion and pyrethrin I. On the other hand, acephate, methamidophos, phoxim, propamocarb, tepraloxydim and trichlorfon were also targets for GC-MS. Moreover, interference peaks for the target ions of 54 pesticides were observed, but these pesticides could be quantitated with qualifier ions. For other pesticides, interference peaks over one-third of the peak area corresponding to LOQ $(0.01 \mu \mathrm{g} / \mathrm{g})$ were not observed.

These results could be attributed to the control of acetonitrile content in extracting. In this method, $15 \mathrm{~mL}$ water was added in extracting to make the acetonitrile content around $70-75 \%$ (the water content of a frozen gyoza dumpling is about $60 \%) .{ }^{14)}$ Lee et al. reported that the use of aqueous acetonitrile (around $70 \%$ of acetonitrile content) brought about good extraction and purification efficiency. ${ }^{17)}$ In addition, cholesterol and fatty acids, which interfered with the qualitation

Table 2. Pesticides that did not meet the criteria for selectivity

\begin{tabular}{rlrl}
\hline No. & \multicolumn{1}{c}{ Pesticide } & Instrument for determination \\
\hline 1 & Acephate & LC-MS & GC-MS \\
2 & Clothianidin & LC-MS & \\
3 & Cycloprothrin & LC-MS & \\
4 & Cymoxanil & LC-MS & \\
5 & Dioxathion & & GC-MS \\
6 & Emamectin B1a FA & LC-MS & \\
7 & Emamectin B1a MFA & LC-MS & \\
8 & Hexythiazox & LC-MS & \\
9 & Methamidophos & LC-MS & GC-MS \\
10 & Oxpoconazole formyl & LC-MS & \\
11 & Phoxim & LC-MS & GC-MS \\
12 & Propamocarb & LC-MS & GC-MS \\
13 & Pyrethrin $I$ & & GC-MS \\
14 & Tepraloxydim & LC-MS & GC-MS \\
15 & Trichlorfon & LC-MS & GC-MS \\
\hline
\end{tabular}


Table 3. Results of recovery test for 496 pesticides

\begin{tabular}{|c|c|c|}
\hline & \multicolumn{2}{|c|}{ Number of pesticides } \\
\hline & $\begin{array}{l}\text { Solvent } \\
\text { standard }\end{array}$ & $\begin{array}{c}\text { Matrix } \\
\text { standard }\end{array}$ \\
\hline met the criteria ${ }^{a)}$ & 378 & 432 \\
\hline \multicolumn{3}{|l|}{ did not meet the criteria } \\
\hline low recovery $(<70 \%)$ & 51 & 29 \\
\hline high recovery $(>120 \%)$ & 34 & 0 \\
\hline considerable variability $^{b)}$ & 13 & 15 \\
\hline \multicolumn{3}{|l|}{ not tested } \\
\hline did not meet the criteria for LOQ & \multicolumn{2}{|c|}{5} \\
\hline did not meet the criteria for selectivity & \multicolumn{2}{|c|}{15} \\
\hline
\end{tabular}

a) The pesticide met the acceptance criteria for recovery and precision. ${ }^{b)}$ The pesticide did not meet the acceptance criteria for repeatability (RSD \%) or intermediate precision (RSD \%).

and quantification of the target pesticides on GC-MS analysis, were eliminated by increasing the amount of packing sorbent (ODS mini-column: from $1 \mathrm{~g}$ to $2 \mathrm{~g}$; PSA mini-column: from $0.2 \mathrm{~g}$ to $0.5 \mathrm{~g}$ ).

\section{2. $L O Q$}

Barban, isoxaflutole, linuron and triforine exhibited low sensitivity when analyzed by LC-MS, and the peaks corresponding to $0.01 \mu \mathrm{g} / \mathrm{g}$ did not meet $\mathrm{S} / \mathrm{N} \geq 10$ in the presence of the frozen gyoza dumpling matrix. DCIP analyzed by GC-MS was highly volatile, so the peak for DCIP that corresponds to $0.01 \mu \mathrm{g} / \mathrm{g}$ also did not meet $\mathrm{S} / \mathrm{N} \geq 10$ because of the reduction in concentration during sample preparation. The other pesticides that were tested (except for the pesticides shown in Table 2) were confirmed to have an LOQ values of $0.01 \mu \mathrm{g} / \mathrm{g}$ $(\mathrm{S} / \mathrm{N} \geq 10)$.

\subsection{Accuracy (recovery) and precision}

The results of the recovery tests for the 496 pesticides are summarized in Table 3, and the details are shown in Supplemental Table S3.

First of all, the analytical precision was evaluated. Highly volatile pesticides (butylate, diphenyl, EPTC and metaldehyde), lipophilic pesticides (mirex and silafluofen) and degradable pesticide (amitraz) exhibited considerable variability. In total, 13 pesticides did not meet the criteria for precision with both the solvent and the matrix-matched standard, while amitraz and bromacil failed in terms of the matrixmatched standard.

Then the recovery was evaluated, excluding pesticides with considerable variability. Eighty-five pesticides were found to not meet the criteria for recovery when the recovery data were calculated using the solvent standard; 34 pesticides showed high recovery (120.4-198.7\%) and 51 showed low recovery $(25.8-69.5 \%)$. All of the pesticides, that showed high recov- ery with the solvent standard, improved to $79.4-119.9 \%$ by calculating using the matrix-matched standard. About $80 \%$ of them were targets for GC-MS analysis, and they included high molecular weight (around 400) compounds (such as pyrethroids, butafenacil, dimethomorph and fluthiacetmethyl). High molecular weight pyrethroids in a solvent standard generally give poor peak shapes. ${ }^{18)}$ This phenomenon causes decrements of the chromatographic response in a solvent standard. This indicated that their high recoveries which were observed with the solvent standard were caused by matrix effects. On the other hand, 21 of the pesticides, which showed low recovery with the solvent standard, improved to $70.1-102.7 \%$ by calculating using a matrix-matched standard, and all of the targets for LC-MS analysis improved, except for amitraz which is easily hydrolyzed. ${ }^{19)}$

The pesticides, that did not meet the criteria for recovery with the matrix standard, included 12 organochlorines (aldrin, hexachlorbenzene and others), 6 pyrethroids (bifenthrin, resmethrin and others) and 3 lipophilic organophosphorous (bromophos-ethyl, chlorethoxyfos and prothiofos). It was considered that they were insufficiently extracted by the acetonitrile or were retained on the ODS mini-column, due to their lipophilicity (their $\log P_{\text {ow }}$ values are approximately more greater than $4 .{ }^{5)}$

Six pesticides (butylate, cypermethrin, diphenyl, etridiazole, flonicamide metabolite and metaldehyde) showed higher recoveries at $0.01 \mu \mathrm{g} / \mathrm{g}$ than those at $0.10 \mu \mathrm{g} / \mathrm{g}$. As a reason, it was considered that following 2 phenomena resulted in more pronounced decreases of these pesticides at $0.01 \mu \mathrm{g} / \mathrm{g}$. Firstly, butylate, diphenyl, etridiazole and metaldehyde were volatilized in preparing the solvent standard solution because of their high-volatility. The results of matrix-matched standard methods showed same results, because the matrixmatched standard was prepared with the standard solution; secondly, cypermethrin and flonicamide metabolite in the solvent standard were adsorbed on active sites in the GC system, as evidenced by the fact that only the recoveries with the solvent standard showed higher recoveries at $0.01 \mu \mathrm{g} / \mathrm{g}$ than that at $0.10 \mu \mathrm{g} / \mathrm{g}$.

Finally, among the 496 pesticides tested, 378 and 432 were found to meet all of the guideline criteria by calculating using the solvent standard and matrix-matched standard methods, respectively.

\section{Matrix effect}

The matrix effect values (recovery calculated using the matrix-matched standard divided by that calculated using the solvent standard) for each pesticide are summarized in Table 4.

More than 367 pesticides $(85 \%$ of pesticides that were tested) showed acceptable matrix effect values ranging from 0.8 to 1.2 for both fortified levels. Forty four pesticides (10.2\%) had low matrix effect values below 0.8 at $0.01 \mu \mathrm{g} / \mathrm{g}$, and $70 \%$ of them were targets for GC-MS analysis.

On the other hand, 21 pesticides $(4.9 \%)$ had high matrix ef- 
Table 4. Distribution of matrix effect value in frozen gyoza dumplings

\begin{tabular}{ccc}
\hline & \multicolumn{2}{c}{ Proportion of pesticides $(\%)^{a)}$} \\
\cline { 2 - 3 } Matrix effect value $^{b)}$ & $0.01 \mu \mathrm{g} / \mathrm{g}$ & $0.10 \mu \mathrm{g} / \mathrm{g}$ \\
\hline$<0.5$ & 0 & 0 \\
$0.5-<0.6$ & 0 & 0 \\
$0.6-<0.7$ & 0.9 & 0 \\
$0.7-<0.8$ & 9.0 & 0 \\
$1.0 \pm 0.2$ & 85.0 & 94.0 \\
$1.2-<1.3$ & 1.4 & 3.2 \\
$1.3-<1.4$ & 1.6 & 1.4 \\
$1.4-<1.5$ & 0.5 & 0.5 \\
$>1.5$ & 1.4 & 0.9 \\
\hline
\end{tabular}

a) $\mathrm{N} 1 / \mathrm{N}_{2} \times 100 . \mathrm{N}_{1}$ : Number of pesticides having each matrix effect value (the leftmost column). $\mathrm{N}_{2}$ : Number of pesticides meeting the acceptance criteria for recovery and precision with the matrix-matched standard. ${ }^{b)} \mathrm{R}_{1} / \mathrm{R}_{2} . \mathrm{R}_{1}$ : Recovery calculated for the matrix-matched standard. $\mathrm{R}_{2}$ : Recovery calculated for the solvent standard.

fect values over 1.2 at $0.01 \mu \mathrm{g} / \mathrm{g}$, and about $85 \%$ of them were targets for LC-MS analysis.

The use of a matrix-matched standard is considered to be preferable for accurate quantitation.

\section{Monitoring results}

We applied the proposed method to the routine analysis of pesticides in 11 frozen gyoza dumplings made in China during FYs 2008-2009. Table 5 summarizes the monitoring results and MRLs of representative ingredients of the dumplings.

Fourteen different pesticides were detected from 8 samples at concentrations ranging from trace levels $(<0.01 \mu \mathrm{g} / \mathrm{g})$ to $0.11 \mu \mathrm{g} / \mathrm{g}$, and $57 \%$ of the total detected numbers were at trace levels. Five of 8 samples contained multi-residues, and 9 different pesticides were detected from a sample at most. Carbendazim, chlorpyrifos and iprodione were frequently detected, and their detection ratios were $46.7 \%, 26.7 \%$ and $26.7 \%$, respectively.

When a pesticide is detected in a processed food, we have to convert the detection level to the residue level in an ingredient of the processed food, and judge whether its residue level is lower than the MRL. The MRLs of the pesticides that could be detected by this routine analysis, are set at relatively high levels for cabbage, chinese chive, welsh onion and porkmuscle which are the main ingredients of the dumplings. Although the composition ratio of the ingredients in these frozen gyoza dumpling samples were not specified, it was considered that the residue levels didn't exceed the MRLs in each ingredient, given that the detection levels much lower

Table 5. Pesticide residues detected from 11 frozen gyoza dumplings during FY 2008-2009

\begin{tabular}{|c|c|c|c|c|c|c|c|c|}
\hline \multirow[b]{2}{*}{ Pesticide } & \multirow{2}{*}{$\begin{array}{l}\text { Detected } \\
\text { number }^{a)}\end{array}$} & \multirow{2}{*}{$\begin{array}{l}\text { Concentration } \\
\qquad(\mu \mathrm{g} / \mathrm{g})\end{array}$} & \multicolumn{6}{|c|}{ MRLs of representative ingredients $(\mu \mathrm{g} / \mathrm{g})$} \\
\hline & & & $\begin{array}{l}\text { Wheat } \\
\text { flour }^{b)}\end{array}$ & $\begin{array}{c}\text { Pork } \\
\text { muscle }\end{array}$ & Shrimp & Cabbage & $\begin{array}{l}\text { Chinese } \\
\text { chive }\end{array}$ & $\begin{array}{l}\text { Welsh } \\
\text { onion }\end{array}$ \\
\hline 3OH-Carbofuran & 1 & Tr. & $0.01^{c)}$ & $0.05^{c)}$ & $0.01^{c)}$ & $0.5^{c)}$ & $0.5^{c)}$ & $1^{c)}$ \\
\hline Carbendazim & $7(4)$ & Tr., $0.01,0.03,0.05,0.11$ & 0.01 & 0.1 & 0.01 & 3 & 3 & 3 \\
\hline Chlorpyrifos & $4(1)$ & Tr., 0.01 & 0.1 & 0.05 & 0.01 & 0.05 & 0.01 & 0.2 \\
\hline p,p'-DDE & 1 & Tr. & $0.01^{d)}$ & $1^{d)}$ & $1^{d)}$ & $0.2^{d)}$ & $0.3^{d)}$ & $0.5^{d)}$ \\
\hline Endosulfan sulfate & 2 & $\operatorname{Tr}$ & $-^{e)}$ & $e^{e)}$ & $e^{e)}$ & $e^{e)}$ & $-^{e)}$ & $e^{e)}$ \\
\hline Fenvalerate & 1 & $\operatorname{Tr}$. & 0.2 & 0.9 & 0.01 & 3.0 & 0.50 & 0.50 \\
\hline Iprodione & $4(3)$ & Tr., $0.01,0.04,0.05$ & 0.01 & 0.2 & 0.01 & 5.0 & 5.0 & 5.0 \\
\hline Iprodione met. & 1 & Tr. & & & & & & \\
\hline Isofenphos-methyl & 1 & $\operatorname{Tr}$. & 0.01 & 0.01 & 0.01 & 0.01 & 0.01 & 0.01 \\
\hline Malathion & 1 & $\operatorname{Tr}$. & 1.2 & 2 & 0.5 & 2.0 & 2.0 & 8.0 \\
\hline Procymidone & $2(2)$ & $0.01,0.10$ & 0.01 & 0.05 & 0.01 & 2 & 5 & 5 \\
\hline Pyrimethanil & $2(1)$ & Tr., 0.02 & 0.01 & 0.05 & 0.01 & 0.01 & 0.01 & 2 \\
\hline Triadimefon & 1 & Tr. & 0.01 & 0.05 & 0.01 & 0.1 & 0.1 & 0.1 \\
\hline Triadimenol & $2(2)$ & $0.02,0.05$ & 0.01 & 0.05 & 0.01 & 1 & 0.5 & 0.2 \\
\hline
\end{tabular}

${ }^{a)}$ Number in parentheses shows the detected number at $\geq 0.01 \mu \mathrm{g} / \mathrm{g} .{ }^{b)}$ except whole grain. ${ }^{c}$ MRLs as Carbofuran. ${ }^{d)}$ MRLs as DDT.

e) Endosulfan sulfate is exempt from regulations in Japan. Tr.: Trace level $(\geq 0.001 \mu \mathrm{g} / \mathrm{g}$, but $<0.010 \mu \mathrm{g} / \mathrm{g})$. Italics: Uniform limit. met.: metabolite. 
than the MRLs.

The applicability of the proposed method for residual pesticides in frozen gyoza dumplings was verified. This method allowed analysis at $0.01 \mu \mathrm{g} / \mathrm{g}$ without any matrix interference and showed good recoveries and good precisions for 432 pesticides. This indicates that the method could be an efficient and reliable tool for regulatory monitoring of many residual pesticides in frozen gyoza dumplings.

On the other hand, these results were based on only the recovery tests that were conducted using the samples to which the working standard was directly added. Therefore, some pesticides (especially lipophilic pesticides) could show lower residual concentrations in lipid samples due to insufficiency of extraction by the acetonitrile. It is necessary to confirm the extraction efficiency by comparing our proposed method to the methods which are able to extract efficiently pesticides from lipid samples.

\section{References}

1) Notification of Ministry of Health Labour and Welfare of Japan, No. 499, Nov. 29 (2005).

2) Notification of Ministry of Health Labour and Welfare of Japan, No. 497, Nov. 29 (2005).

3) Y. Okamoto, S. Takatori, Y. Kitagawa, M, Okihashi, N. Fukui, H. Murata, T. Sumimoto, Y. Tanaka and H. Obana: J. Food Hyg. Soc. Jpn. 50, 10-15 (2009) (in Japanese).

4) Y. Kitagawa, M, Okihashi, S. Takatori, Y. Okamoto, N. Fukui, H. Murata, T. Sumimoto and H. Obana: J. Food Hyg. Soc. Jpn. 50, 198-207 (2009) (in Japanese).

5) K. Koeduka, M. Ishii, J. Yamamoto and S. Yamabe: Annual report of Okayama Prefectural Institute for Environmental Science and Public Health 33, 135-140 (2009) (in Japanese).

6) N. Matsumoto, M, Yoshikawa, K. Eda, A. Kobayashi, M. Yokoshima, M. Murakami and H. Kanekita: J. Food Hyg. Soc. Jpn. 49, 211-222 (2008) (in Japanese).

7) E. Hatakeyama, C. Akutsu, H. Kajita and T. Sugawara: Annual report of The Research Institute for Environmental Sciences and Public Health of Iwate Prefecture 8, 81-86 (2008) (in Japanese).

8) Division of Food and Environmental Hygiene: Annual report of Kyoto City Institute of Health and Environmental Sciences 74, 121-128 (2008) (in Japanese).

9) Y. Makabe, F. Miyamoto, H. Hashimoto, K. Nakanishi and Y. Hasegawa: J. Food Hyg. Soc. Jpn. 51, 182-195 (2010) (in Japanese).

10) Y. Akiyama, N. Yoshioka and T. Matsuoka: "Pesticide Chemistry" ed. by H. Ohkawa, H. Miyagawa and P. W. Lee, WilleyVCH, Weinheim, pp. 395-399, 2007.

11) Y. Akiyama, N. Yoshioka, T. Matsuoka, S. Akamatsu and T. Mitsuhashi: Journal of The Japan Quarantine Medical Association 12, 92-98 (2010) (in Japanese).

12) Y. Akiyama, T. Matsuoka, N. Yoshioka, S. Akamatsu and T. Mitsuhashi: J. Pestic. Sci. 36, 66-72 (2011).

13) Y. Akiyama, T. Matsuoka and N. Yoshioka: Abstr. 47th Annu. Meeting of Japan Association of Prefectural and Municipal Public Health Institutes, pp. 68-69, 2010 (in Japanese).

14) Ministry of Education, Culture, Sports, Science and Technology, STANDARD TABLES OF FOOD COMPOSITION IN JAPAN Fifth Revised and Enlarged Edition (2005); http://www. mext.go.jp/b_menu/shingi/gijyutu/gijyutu3/toushin/05031802. htm

15) Director Notice of Department of Food Safety, Ministry of Health Labour and Welfare of Japan, Syoku-An No. 1115001, Nov. 15, 2007; http://www. mhlw.go.jp/topics/bukyoku/iyaku/ syoku-anzen /zanryu3 /d1/071115-1.pdf

16) T. Matsuoka, Y. Akiyama and T. Mitsuhashi: J. Pestic. Sci. 36, 73-78 (2011).

17) S. M. Lee, M. L. Papathakis, H. C. Feng, G. F. Hunter and J. E. Carr: Fresenius J. Anal. Chem. 339, 376-383 (1991).

18) C. Sachez-Brunete, B. Albero, G. Martin and J. L. Tadeo: Anal Sci. 21, 1291-1296 (2005).

19) C. D. S. Tomlin (ed.): "A World Compendium: The Pesticide Manual, 14th edition," British Crop Production Council, U.K., 2006. 